Artigo / Article

\title{
Monitoração molecular da Leucemia Mielóide Crônica na era do imatinibe
}

\section{Molecular monitoring of Chronic Myeloid Leukemia in the imatinib era}

Israel Bendit

\section{Introdução}

No final de 2006, Druker e cols. relataram os resultados do estudo IRIS (International Randomized Study of Interferon versus STI571) após cinco anos de acompanhamento dos pacientes com diagnóstico de Leucemia Mielóide Crônica (LMC) tratados com mesilato de imatinibe (MI) em primeira linha. ${ }^{1}$ Os resultados mostram resposta citogenética completa (ausência do cromossomo $\mathrm{Ph}$ ) em $69 \%$ dos casos ao final de 12 meses de tratamento e $87 \%$ ao final dos 60 meses. A sobrevida global estimada ao final de cinco anos de acompanhamento é de $89 \%$ com $7 \%$ dos pacientes progredindo para a fase acelerada (FA) ou crise blástica (CB). Este mesmo estudo ressalta a importância da resposta molecular que estaria associada a alta sobrevida livre de progressão. Esta resposta molecular é determinada pela redução do número de transcritos do gene $B C R-A B L$, produto da translocação recíproca $\mathrm{t}(9 ; 22)$ resultando no cromossomo 22 mais curto, conhecido como cromossomo $\mathrm{Ph}$. Este gene quimérico se caracteriza pela justaposição do gene $A B L$, localizado inicialmente no cromossomo 9, ao gene $B C R$, no cromossomo 22 , ficando sujeito à regulação deste. O produto final é uma oncoproteína BCR-ABL com atividade tirosino quinase de localização citoplasmática e crucial na patogênese da LMC. ${ }^{2}$
A metodologia aceita atualmente para a monitoração da resposta molecular através da expressão de BCR-ABL é o PCR, acrônimo para Polymerase Chain Reaction, quantitativo (Q-PCR) em pacientes tratados principalmente com o MI. Inúmeros estudos foram publicados quanto aos ensaios utilizando a técnica de Q-PCR, e os resultados dependem principalmente do gene controle interno utilizado em cada instituição. Os genes controle internos atualmente utilizados na grande maioria dos centros são $B C R, A B L$ e $G U S B$ (betaglucoronidase). Estes genes são atualmente aceitos por produzirem resultados confiáveis. Não podemos esquecer também da importância da qualidade do material biológico (RNA) a ser analisado; isto tem uma relação direta com a coleta, armazenamento e envio do sangue periférico ou medula óssea ao laboratório que irá realizar o ensaio de Q-PCR. O que se sabe é que o sangue periférico coletado em EDTA (ácido etilenodiaminotetracético) e mantido a temperatura ambiente resulta na degradação do transcrito $B C R-A B L$ em aproximadamente $20 \%$ em 24 horas e até $50 \%$ em 48 horas. ${ }^{3}$ Fica acordado neste consenso que o envio de amostra deverá ser o mais rápido possível para o laboratório que realizará a determinação do número de cópias do transcrito $B C R-A B \mathrm{~L}$, isto é, antes de 24 horas desde a coleta ou acondicionada em gelo quando não for possível o envio em 24 horas.

Professor colaborador do Serviço de Hematologia e Hemoterapia da Faculdade de Medicina da USP-SP. Chefe do Laboratório de Biologia Tumoral do Hemocentro de São Paulo-SP.

Correspondência: Israel Bendit

Rua Dr. Candido Espinheira, 155

05.004-000 - São Paulo-SP - Brasil

E-mail:isbendit@usp.br 
Recentemente foram publicadas algumas recomendações em relação à LMC. ${ }^{4} \mathrm{O}$ objetivo primário deste encontro visava a harmonização nas diferentes metodologias que determinam o número de transcritos $B C R-A B L$ com a utilização de uma escala internacional. Para a utilização desta escala internacional, cada laboratório necessitaria determinar o baseline ou linha de base standard, que seria correspondente a $100 \%$ de $B C R-A B L$ ao diagnóstico, e a resposta molecular maior corresponderia à redução de $3 \log$ desta linha de base definida ou $0,1 \% B C R-A B L$ na escala internacional. Desta forma, os laboratórios expressariam os resultados na mesma magnitude tornando o monitoramento mais uniforme entre instituições que tratam pacientes com LMC.

O monitoramento molecular deverá ser de forma seriada após a obtenção da Resposta Citogenética Completa (RCC) em sangue periférico e o intervalo entre amostras deverá ser a cada três meses. A realização da citogenética ou FISH de medula óssea estaria indicada nos casos onde haveria a presença de qualquer anormalidade cromossômica em clone $\mathrm{Ph}+$ ou Del 9p (este assunto será abordado em outra sessão deste consenso). ${ }^{5}$

O objetivo primário deste monitoramento seriado é a identificação precoce, pelo aumento no número destes transcritos, de uma subpopulação de células $B C R-A B L$ com mutação no gene $A B L$, o que acarretaria no desenvolvimento de resistência à terapia com MI. O grupo Gimema-CML preconiza um aumento de até cinco vezes no valor da relação $B C R$ $A B L / A B L$ ou $B C R$ ou $G U S B$. Por outro lado, o grupo australiano defende um incremento de até duas vezes na mesma relação mencionada acima em duas amostras consecutivas com intervalo de um mês. Na última reunião do Consenso Brasileiro de Leucemia Mielóide Crônica ficou determinado que se levasse em conta o aumento de cinco vezes o valor da relação $B C R-A B L / A B L$ ou $B C R$ em duas amostras consecutivas com intervalo de um mês entre as amostras.

O LeukemiaNet, em 2006, reportou algumas recomendações para o acompanhamento de pacientes com LMC somente na fase crônica tratados com MI, no qual salientaram a importância da monitoração molecular. Ficou determinado que pacientes que não atingissem a RMM aos 18 meses de tratamento seriam classificados como resposta subótima. ${ }^{5}$ Baseado nestas recomendações ficou determinado, na reunião do Consenso Brasileiro, que amostras de sangue periférico destes pacientes deverão ser analisadas para presença de mutação no gene $A B L$.

Nesta revisão tivemos o cuidado de abordar os principais pontos quanto à monitoração molecular e a sua importância. Deve-se deixar claro que estas recomendações poderão sofrer alterações com o decorrer do tempo.

\section{Abstract}

Treatment of chronic myeloid leukemia (CML) has changed since the introduction of imatinib mesylate (IM) 10 years ago. IM acts as a target therapy against the $B C R-A B L$ gene by inhibiting its tyrosine kinase activity. This revolution in treating CML compels the introduction of molecular techniques, such as real time quantitative polymerase chain reaction (RQ-PCR) to monitor the response to IM by providing an accurate measurement of the degree to which the $B C R-A B L$ transcript is reduced or an early detection of loss of response identified by a rising level of $B C R-A B L$. In this review, we summarize the Brazilian $C M L$ consensus regarding the main procedures used to monitor CML patients treated with IM. Rev. bras. hematol. hemoter. 2008; 30(Supl.1):20-21.

Key words: $B C R-A B L$; quantitative $P C R$; $C M L$; mutation analysis.

\section{Referências Bibliográficas}

1. Brian J, Druker MD, Guilhot F, O’Brien SG, Gathmann I, Kantarjian $\mathrm{H}$, et al. Five-year follow-up of patients receiving imatinib for Chronic Myeloid Leukemia. N Eng J Med. 2006;356(17):1780.

2. Daley GQ, Van Etten RA, Baltimore D. Induction of chronic myelogenous leukemia in mice by the P210bcr/abl gene of the Philadelphia chromosome. Science. 1990;247:(4944):824-30.

3. Branford S, Cross NC, Hochhaus A, Radich J, Saglio G, Kaeda J, et al. Rationale for the recommendations for harmonizing current methodology for detecting BCR-ABL transcripts in patients with chronic myeloid leukaemia. Leukemia 2006;20:1925-30.

4. Hughes T, Deininger M, Hochhaus A, Branford S, Radich J, Kaeda J, et al. Monitoring CML patients responding to treatment with tyrosine kinase inhibitors: review and recommendations for harmonizing current methodology for detecting BCR-ABL transcripts and kinase domain mutations and for expressing results. Blood. 2006;108:28-37.

5. Baccarani M, Saglio G, Goldman J, Hochhaus A, Simonsson B, Appelbaum F, et al. Evolving concepts in the management of chronic myeloid leukemia: recommendations from an expert panel on behalf of the European LeukemiaNet. Blood. 2006; 108:1809-20.

O tema apresentado e o convite ao autor constam da pauta elaborada pelos co-editores, Professor Ricardo Pasquini e Professor Cármino Antonio de Souza.

Avaliação: Co-editores e um revisor externo. Publicado após revisão e concordância do editor. Conflito de interesse: não declarado.

Recebido: 21/2/2008

Aceito: 28/03/2008 